\title{
Spectral and Power-Efficiency Trade-off in Fixed-Grid Optical Networks
}

\author{
Sridhar Iyer and Shree Prakash Singh
}

\begin{abstract}
The improvement of spectral efficiency in the MLR networks can be obtained by the reduction of sub-band spacing, or by minimizing the spacing of the sub-bands that operate at varied data rates. However, due to the presence of physical layer impairments, minimization in sub-band spacing leads to adverse effects on the channel(s) transmission reach. As a result there occurs an increase in the consumed power due to the requirement of increase in regeneration of the signal. In the current work we propose an improved DWDM grating in view of obtaining higher spectral efficiency. For a system, with and without Forward Error Correction capabilities (i) for various SLR solutions, we find and compare power consumption values of the components with respect to the total traffic, and (ii) for different MLR and SLR solutions, for a fixed QoT, we evaluate the minimum values of the sub-band and the channel spacing, and also evaluate and compare the power-efficiency with the distance of transmission.
\end{abstract}

Keywords-mixed line rate, single line rate, power-efficiency, spectral-efficiency, sub-band spacing.

\section{INTRODUCTION}

For over the last decade, with an increase in the heterogeneous traffic demands, bandwidth utilization in wavelength division multiplexed (WDM) networks has doubled every two years [1]. Hence, the backbone WDM network operators have had to ensure a definite quality of transmission (QoT), and network accessibility [2]. To pursue technologies that can be adopted by the next generation core networks, it is imperative that channel rates beyond the legacy $10 \mathrm{Gbps}(10 \mathrm{G})$ be supported. Hence, the $10 \mathrm{G}$ data-rate (DR) channels have had to be altered to 40 and/or $100 \mathrm{G}$ line-rate (LR) channels [3]. However, increasing the DRs results in higher capital expenditure (CapEx), and also leads to the underutilization of the network resource(s) [4]. A mixed line rate (MLR) network is able to support $10 / 40 / 100 \mathrm{G}$ on the various wavelengths in a single fiber, and is both, cost- and power-efficient [5]. Further, implementing higher LRs mitigates the bandwidth issues within the network. However, the aforementioned (i) may not be power efficient [6], [7], and (ii) is only a short-term solution since, channel placing within the band of frequency of an optical fiber is not infinite [8].

Currently, operators are investigating solutions that allow for an increase in only spectral-efficiency (SE) [9], [10], which however, increases the physical layer impairments (PLIs)

Manuscript received June 24, 2017; revised August 1, 2017.

Sridhar Iyer is with Department of ECE, Jain College of Engineering, T S. Nagar Hunchanatti Cross-Machhe, Belagavi, Karnataka, India - 590014; e-mail: sridhariyer1983@gmail.com.

Shree Prakash Singh is with Division of ECE, Netaji Subhas Institute of Technology, Sector-3, Dwarka, New Delhi-110078. e-mail: sps_nsit@yahoo.co.uk. effects. This results in a reduction of the transmission reach (TR) [11], due to which, in order to guarantee a fixed QoT, the optical signals may require $3 \mathrm{R}$ (re-amplification + re-timing + re-shaping) regeneration involving the optical-to-electrical-tooptical (OEO) process [4]. Hence, the power-efficiency (PE) decreases owing to the need for increased equipment(s) at a few chosen nodes within the network. Thus, increase of the operational expenditure (OpEx) and environmental impacts due to greater emissions of greenhouse gases (GHGs) [7], [11][13] occurs if, solutions only increase the SE; simultaneously exceeding the power consumption required for transmitting the information. Therefore, the SE, the TR, and the power consumption can be traded-off; and for optimizing design of the MLR network, it is imperative to investigate the mutual influence of these parameters.

The SE and PE trade-off in MLR networks has not been thoroughly investigated in the literature. In [12], the authors have modelled the systems and the components in terms of their power consumption; however, they have not considered the efficient utilization of limited frequency resources of the transmission band being used. The authors in [14] have considered an efficient network design to address the relationship between the QoT and power consumption, with signal quality guarantee. However, the influence of various spectral efficient solutions on system power consumption is not investigated. In [15], the authors have studied impact of the coherent and the non-coherent technologies on the power consumption in translucent WDM networks. However, no conclusions have been drawn on the maximum achievable transparent reach. In our previous work [16], for different MLR and Single Line Rate (SLR) systems, we compared PE, and also investigated $\mathrm{PE}$ and the SE trade-off in a WDM system. However, our study assumed that the WDM system does not have the forward error correction (FEC) capability.

We extend the work presented in [16] by conducting a more in-depth study for a WDM system with FEC capabilities. Firstly, in view of obtaining a higher SE, we propose an improved Dense WDM (DWDM) grating, which is an extension of ITU-T recommendation G.694.1 [17]. Further, for different SLR solutions, we find and compare component(s) power consumption values as a variation of the total traffic. Also, for different MLR and SLR solutions, (i) for fixed QoT, we evaluate minimum values of the sub-band and the channel spacing, and (ii) calculate and compare PE with a variation of the transmission distance. From the results, for an increase in the overall capacity, considering the SE, the PE, and the TR at the same time, in presence or absence of the FEC capabilities, use of appropriate DRs and modulation format(s) (MFs) can 
be then be concluded upon.

Rest of the paper is structured as follows: In Section II, we detail the WDM system model and simulation set-up. Section III presents and discusses various simulation results obtained. Finally, Section IV concludes the study.

\section{System Model and Simulation Setup}

The components consuming power in a WDM system can be dependent or independent [11], [12] of the DR and the MF. In this study, power consumption (i) due to only transponders (TSPs) and 3R regenerators (3Rs) is considered, and (ii) by amplifiers is assumed independent of the signal MF and DR.

Fig. 1 shows the WDM link model used in our current study, which is similar to a link within a network topology, and corresponds to a ten channel system [16]. Also, since our focus is only on the maximum acceptable SE for transmission over a single span, we do not consider the deployment of fixed-gain inline and pre-amplifiers. For SLR cases, the configuration consists of only (i) 10G NRZ - OOK, or (ii) 40G NRZ DPSK, or (iii) $100 \mathrm{G}$ DP - QPSK channels. In case of MLRs, wavelengths are grouped as (i) 10G NRZ-OOK - 40G NRZDPSK, (ii) 40G NRZ-DPSK 100G DP-QPSK, and (iii) 10G NRZ-OOK - 100G DP-QPSK. At the receiver, to evaluate the QoT, the wavelengths are arranged as described in [16], and the $Q$-factor [17] is used as the performance metric.

To simulate the considered WDM link, we use MatLab and the OptSim ${ }^{\mathrm{TM}}$ software in which, transmitters, receivers filter block diagrams, and their descriptions for NRZ-OOK, NRZ-DPSK and DP-QPSK are as detailed in [16], [18], [19]. A $10 \mathrm{dBm}$ fixed output power level is set for the Erbium Doped Fiber Amplifier (EDFA) [20], [21]. For the standard single mode fiber (SSMF) and the chromatic dispersion compensation module (DCM), their different parameter values such as, the length, the attenuation, the core-area, the nonlinear refractive index, and dispersion are as mentioned in [17], [20], [21]. In regard to PLIs, we use the mathematical model developed in [16]. The simulations are conducted for transmission and/or regeneration of $1 \mathrm{Tbps}$ of total data, and for an individual DR, values of power consumption of TSPs and 3Rs have been evaluated based on data given in [22]-[26]

\section{A. Proposed DWDM Grating Scheme}

The ITU-T recommendation (G.694.1) [27] can be considered to assign the central frequencies (or wavelengths) of the channels. G.694.1 specifies both, a fixed and an elastic

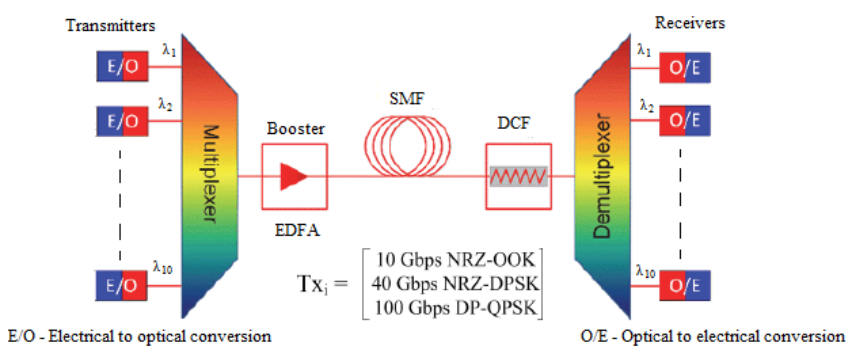

Fig. 1. Description of the WDM link model used in the study.
DWDM grating. It has been imperative to introduce the elastic grating since, the fixed grating works well only when all the transmission channels operate at the same DR and/or the MF. However, when multiple DRs or MFs are used, the fixed grating results in either (i) overlapping of the channels, or (ii) inefficient utilization of the frequency resources of the fiber. Further, in case of a fixed grating, G.694.1 determines only the central frequencies of the channels at different channel spacing values (e.g., 200/100/50/25/12.5 GHz) whereas, in the case of an elastic grating, in addition to determination of the channel central frequencies, G.694.1 also determines the width of the frequency slot. Specifically, for the assignment of the central frequency, a step of $6.25 \mathrm{GHz}$ is considered, i.e.:

$f=193.100+n \cdot 0.00625[\mathrm{THz}], \quad n=0, \pm 1, \pm 2, \pm 3 \ldots$

and for the determination of the frequency slot width, the step value is doubled:

$$
\Delta f_{\text {width }}=0.01250 \cdot m[\mathrm{THz}], \quad m=1,2,3 \ldots
$$

It must also be noted that in case of a fixed DWDM grating, value of any subsequent channel spacing is obtained by dividing the previous channel spacing value by ' 2 '.

In this work, we propose an improvement on the grating wherein, a smaller step is used at each varying channel spacing value. Specifically, for improving SE, we use an intermediate value corresponding to the arithmetic mean. This value is evaluated by considering interval values of the two adjacent channels, and such an approach ensures that a very small variation step for channel spacing can be obtained. However, a closer channel arrangement within the transmission spectrum results in a larger PLI effect(s) from the adjacent channels. In order to estimate the SE improvement that can be achieved by the proposed grating, an MLR system was simulated. The system, as shown in Fig. 1, consisted of 10 channels, and was configured as follows: $10 \mathrm{G}$ NRZ-OOK in channels 1,4 , and 7, 40G NRZ-DPSK in channels 3, 6, and 9, and 100G DP-QPSK in channels 2, 5, and 8. From the results it was found that if, for the channel spacing, an unmodified fixed DWDM grating is used, then the maximum achievable SE is $0.20 \mathrm{bit} / \mathrm{s} / \mathrm{Hz}$. However, use of the proposed grating scheme enables an achievement of $0.27 \mathrm{bit} / \mathrm{s} / \mathrm{Hz}$ of the SE. It was also observed that the SE can be further improved to a value of $0.42 \mathrm{bit} / \mathrm{s} / \mathrm{Hz}$ if, the unequal channel placement is used.

Overall, compared to the ITU-T defined solution, with the proposed grating scheme, an increase in the SE by twice the amount can be achieved. For results that follow, simulations have been conducted by using the proposed DWDM grid.

\section{Simulation Results and Discussion}

This section discusses the obtained simulation results.

\section{A. Power Consumption Variation with the Total Traffic}

In the current study, the functionality(s) and schematic(s) of the TSPs and the 3Rs are as detailed in [25]. In Table I] we have listed the major components that may be part of a TSP and a $3 R$. A $3 R$ is assumed to be a two half-TSP combination 
TABLE I

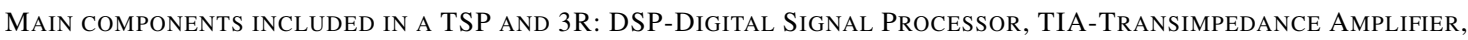
ADC-ANAlog-To-Digital CONVERTER, OTU-Optical ChanNel TRANSPORT Unit.

\begin{tabular}{ccccccc}
\hline & Component & TSP & $\begin{array}{c}10 \mathrm{G} \\
\text { NRZ-OOK }\end{array}$ & $\begin{array}{c}40 \mathrm{G} \\
\text { NRZ-DPSK }\end{array}$ & $\begin{array}{c}\text { 100G } \\
\text { DP-QPSK }\end{array}$ & $\begin{array}{c}3 \mathrm{R} \\
\text { Regenerators }\end{array}$ \\
\hline Client end & Client card & + & 1 & 4 & 10 & NA \\
& Framer & + & 1 (OTU2) & 1 (OTU3) & 1 (OTU4) & NA \\
E/O & Drivers & + & 1 & 1 & 4 & $(\times 2)$ \\
modulation & DSP & + & 0 & 0 & 0 & $(\times 2)$ \\
& Laser (on-off) & + & 1 & 1 & 1 & $(\times 2)$ \\
O/E & Local oscillator & + & 0 & 0 & 1 & $(\times 2)$ \\
receiver & Photodiode & + & 1 & 2 & 4 & $(\times 2)$ \\
& ADC & + & 0 & 0 & 4 & $(\times 2)$ \\
& DSP & + & 0 & 0 & 1 & $(\times 2)$ \\
Client end & Deframer & + & $1($ OTU2) & $1($ OTU2) & $1($ OTU4) & NA \\
& Client card & + & 1 & 4 & 10 & NA \\
\hline
\end{tabular}

TABLE II

POWER CONSUMPTION VALUES OF TSPS AND 3RS.

\begin{tabular}{|c|c|c|c|c|}
\hline $\begin{array}{c}\text { Line rate } \\
\text { (Gbps) }\end{array}$ & $\begin{array}{c}\text { Modulation } \\
\text { Format }\end{array}$ & Component & $\begin{array}{c}\text { Power } \\
\text { (in Watts) }\end{array}$ & $\begin{array}{l}\text { TSP Power (in Watts) } \\
\text { obtained from the } \\
\text { Reference }\end{array}$ \\
\hline 10 & NRZ-OOK & $\begin{array}{l}\text { TSP [with/without FEC] } \\
\text { 3R [with/without FEC] }\end{array}$ & $\begin{array}{l}{[130 / 125]} \\
{[125 / 120]}\end{array}$ & $34 \mid 11]$ \\
\hline 40 & NRZ-DPSK & $\begin{array}{l}\text { TSP [with/without FEC] } \\
\text { 3R [with/without FEC] }\end{array}$ & $\begin{array}{l}{[840 / 800]} \\
{[650 / 600]}\end{array}$ & 85 22 \\
\hline 100 & DP-QPSK & $\begin{array}{l}\text { TSP [with/without FEC] } \\
\text { 3R [with/without FEC] }\end{array}$ & $\begin{array}{l}{[1260 / 1200]} \\
{[1450 / 1400]}\end{array}$ & 13923 \\
\hline
\end{tabular}

(marked as ' $(\times 2)$ ' in Table I). This assumption corresponds to one $3 \mathrm{R}$ used for the reception and one for re-transmitting the regenerated signal; however, without the client end, which comprises of the client cards, framer or de-framer (marked as N.A. in Table II). It must be noted though that (i) the number and the type of components may vary as per a specific DR and a MF, and (ii) in view of simplicity, in Table I. we have specified only a subset of all the TSP and the 3R types (i.e. 10G NRZ-OOK, 40G NRZ-DPSK, and 100G DP-QPSK) which have been considered in the current study. However, the same principle will be applicable to all the other type(s) of TSPs and 3Rs.

Based on the data in [25], and the assumptions described in [16], values of the power consumption are evaluated, and then datasheets are used to benchmark the obtained values. For the different SLRs, values of TSPs and 3Rs power consumptions are then calculated. The obtained results are presented in Table II using which, for different traffic values, we evaluate the 10/40/100G TSPs and the 3Rs power consumption values. The results are an aid in choosing 10/40/100G wavelength(s) combination that guarantees the least overall component(s) (TSPs and 3Rs) consumed power for every total traffic value.

Based on the results from Table II] we determine the number of 10/40/100G components required for the transmission of a particular total traffic, for a system with and without FEC capabilities (see Figs. 2(a), 2(b) and 2(c)).

It can be observed from the figures that

1) In choosing a MF, if the only criteria is the PE of a TSP, then irrespective of the total traffic, for transmitting the data, the 10G NRZ-OOK and the 40G NRZ-DPSK TSPs number must be no more than (i) 30 and 10 respectively, for system without FEC, and (ii) 40 and 20 respectively, for a system with FEC. This ensures the least TSPs overall power consumption.

2) Irrespective of the presence or the absence of FEC capability, the numbers of $100 \mathrm{G}$ DP-QPSK TSPs grows with total traffic since; such TSPs have the highest PE.

3) For $3 R s$, the lowest total power consumption is obtained when, for a system without and with FEC,

(i) independent of the total traffic, no more than 40 and 50 10G NRZ-OOK 3Rs are used, respectively, and

(ii) a constant (5 and 10, respectively) amount of $100 \mathrm{G}$ DP-QPSK 3Rs are deployed, respectively.

4) For a system without and with FEC capability, the amount of 40G NRZ-DPSK 3Rs grows with the total traffic due to their high $\mathrm{PE}$.

Using the results from Table II for the various SLRs and a system without and with FEC capabilities, we analysed the power consumed by TSPs and 3Rs with respect to the mean total traffic (see Fig. 3). The obtained values of power of the TSPs and the 3Rs, (as in Table II), are shown with arrows on Y-axis of Fig. 3. It can be observed from the figure that

1) For capacities less than approximately $80 \mathrm{Gbps}$, the largest PE can be obtained by using the 10G NRZ-OOK TSPs and 3Rs.

2) As capacities increase beyond approximately $100 \mathrm{Gbps}$,

(i) $100 \mathrm{Gbps}$ TSPs are the most power efficient, and

(ii) $40 \mathrm{Gbps} 3 \mathrm{Rs}$ use lesser power in comparison to the 10 Gbps and 100 Gbps 3Rs.

3) With an increase in the capacity, the 100G DP-QPSK TSPs number increases due to their highest PE. 


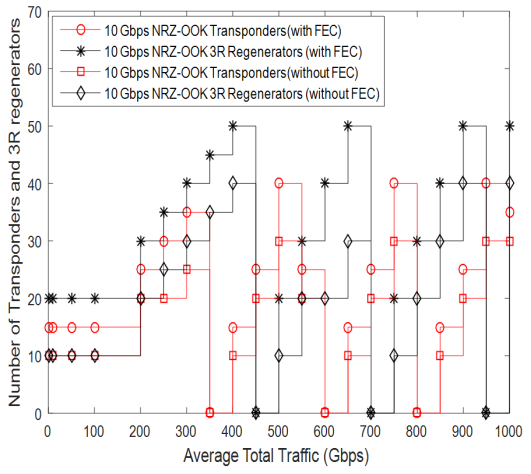

(a)

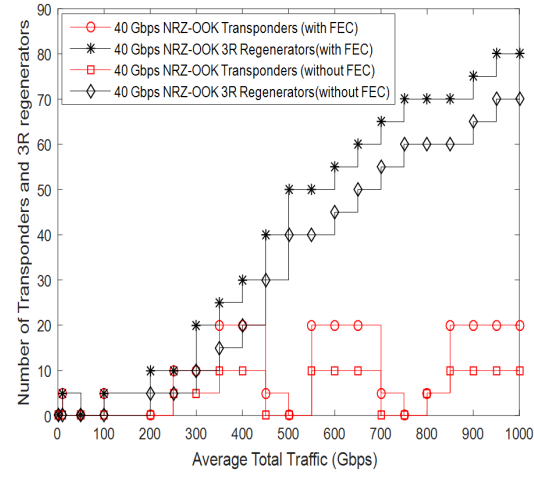

(b)

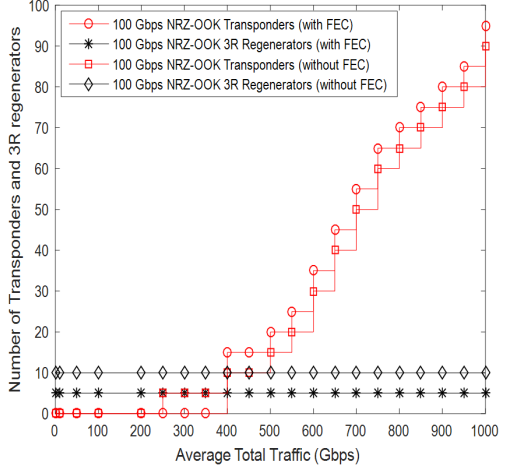

(c)

Fig. 2. To transmit a given amount of total traffic for a WDM system with and without FEC capabilities, the required numbers of (a) 10G NRZ-OOK, (b) 40G NRZ-DPSK, and (c) $100 \mathrm{G}$ DP-QPSK, TSPs and 3Rs.

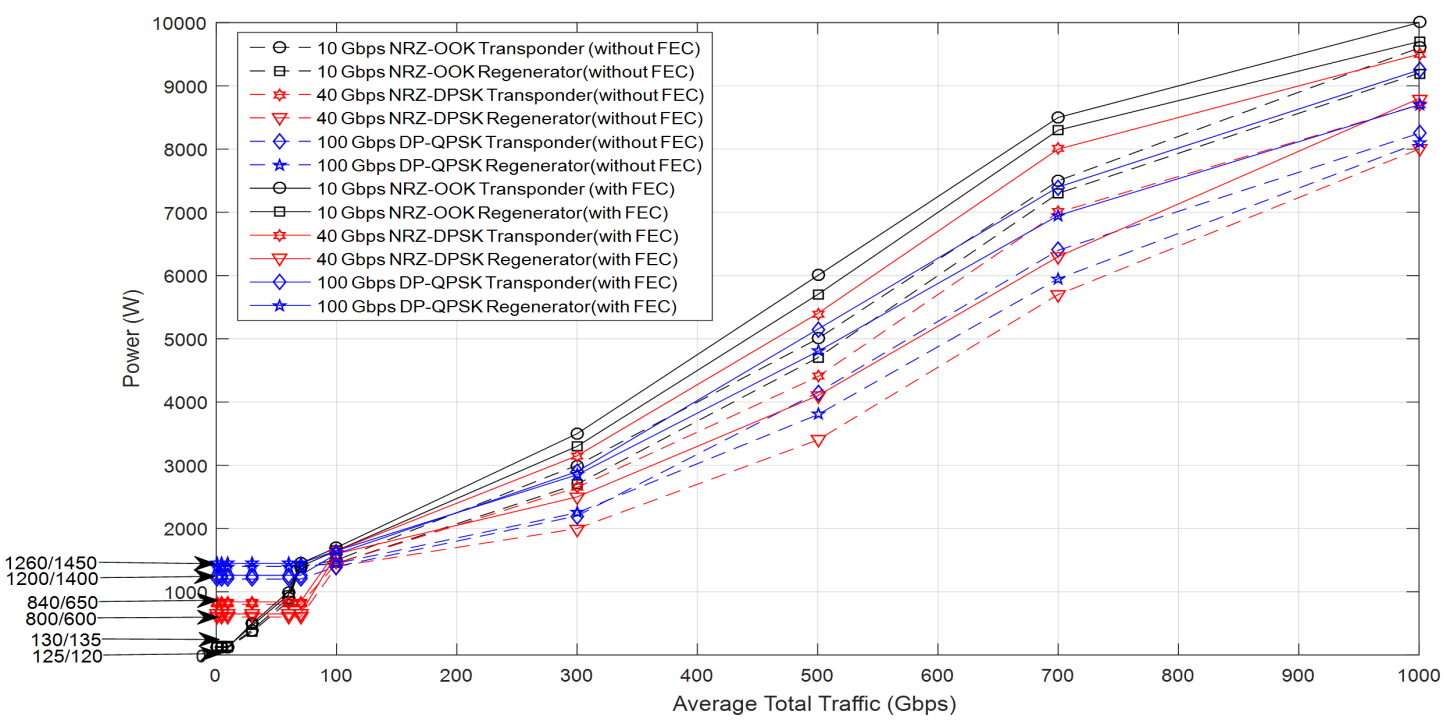

Fig. 3. Consumption of power for various TSPs and 3Rs for different line rates with respect to the mean total traffic for a WDM system with and without FEC capabilities.

4) Compared to a system without FEC, when FEC is introduced, power of the TSPs and that of the 3Rs of all the types is higher for every total traffic value, since with the FEC capability, additional bits are introduced which increases the transmission power.

Overall, it can be deduced that the largest PE can be obtained in the case of a MLR network with large transmission capacity(s) if 100 Gbps TSPs are combined with 40 Gbps 3Rs. Also, with the increase in transmission distance or the SE, due to the requirement of more regeneration, instead of TSPs, the 3 Rs define the power consumption values needed for the transmission.

\section{B. Channel Spacing versus QoT}

When the accommodated amount of traffic depends on the available bandwidth, the allocated width(s) of the sub-band for any channel needs to be accounted for along with the MF and the DR. In view of the aforementioned, in the MLR and SLR systems, considering the channel which is most distorted, we evaluated the $Q$-factor values with respect to the channel spacing, for lengths of span of $50 \mathrm{~km}, 80 \mathrm{~km}$ and $120 \mathrm{~km}$. In our simulations, for system with and without FEC capabilities, the requisite BER value is set to $10^{-15}$ ( $Q=8$ or $18.06 \mathrm{~dB}$ on electrical scale) and $10^{-12}(Q=7$ or $16.90 \mathrm{~dB}$ on electrical scale), respectively. The bit error rate (BER) threshold value is set to higher value when FEC is used since, additional bits are padded for error correction, which increases the total bit-rate from $10 / 40 / 100 \mathrm{G}$ to $10.709 / 43.018 / 127.16 \mathrm{G}$, respectively. As all the system channels are set to generate BER values greater than $10^{-15}$ or $10^{-12}$, we use a single BER ( $Q$-factor) value for multiple DRs. For the aforementioned, we evaluate the largest SE for every MF, and then find the least acceptable channel spacing which guarantees that the most degraded channel always has a BER $\leq 10^{-15}$ or BER $\leq 10^{-12}$. Hence, if it is ensured that the $\mathrm{SE}$ is equal to or less than the maximum value, BER values of all the channels are greater than $10^{-15}$ or $10^{-12}$. The obtained channel spacings are then referred to as the 'minimum acceptable channel spacing'. From the results (see Figs. 4(a), 4(b) and 4(c)), for the SLR cases, it is seen that 


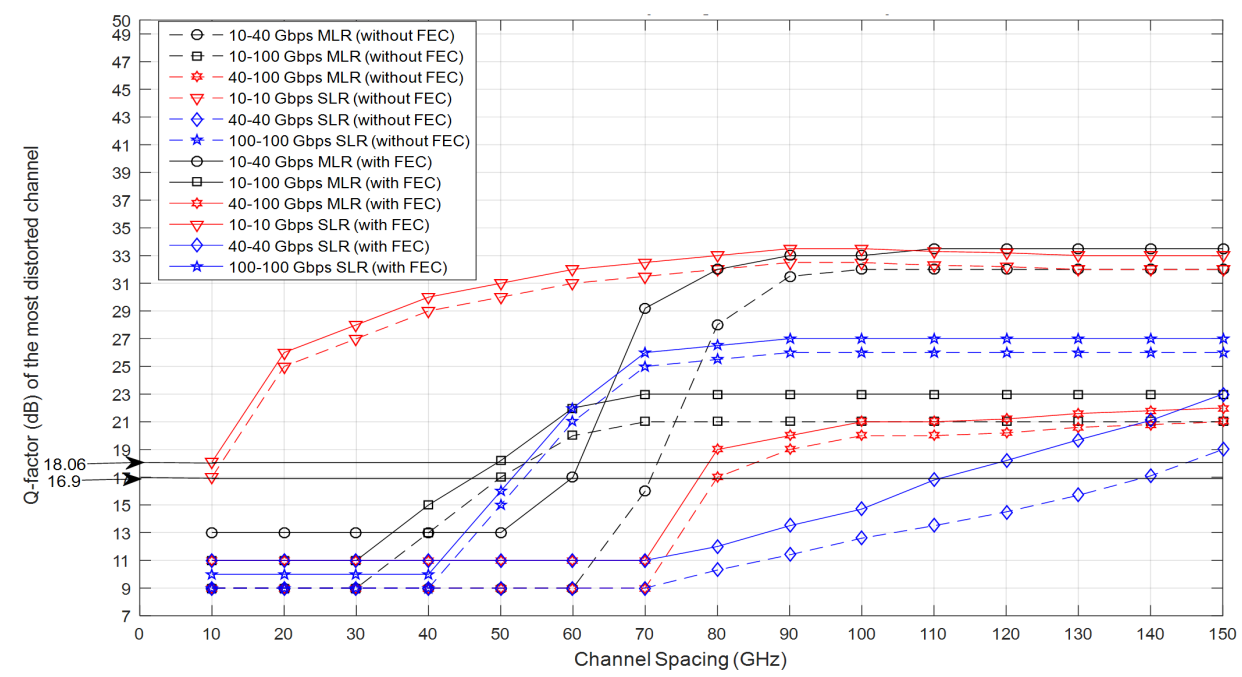

(a)

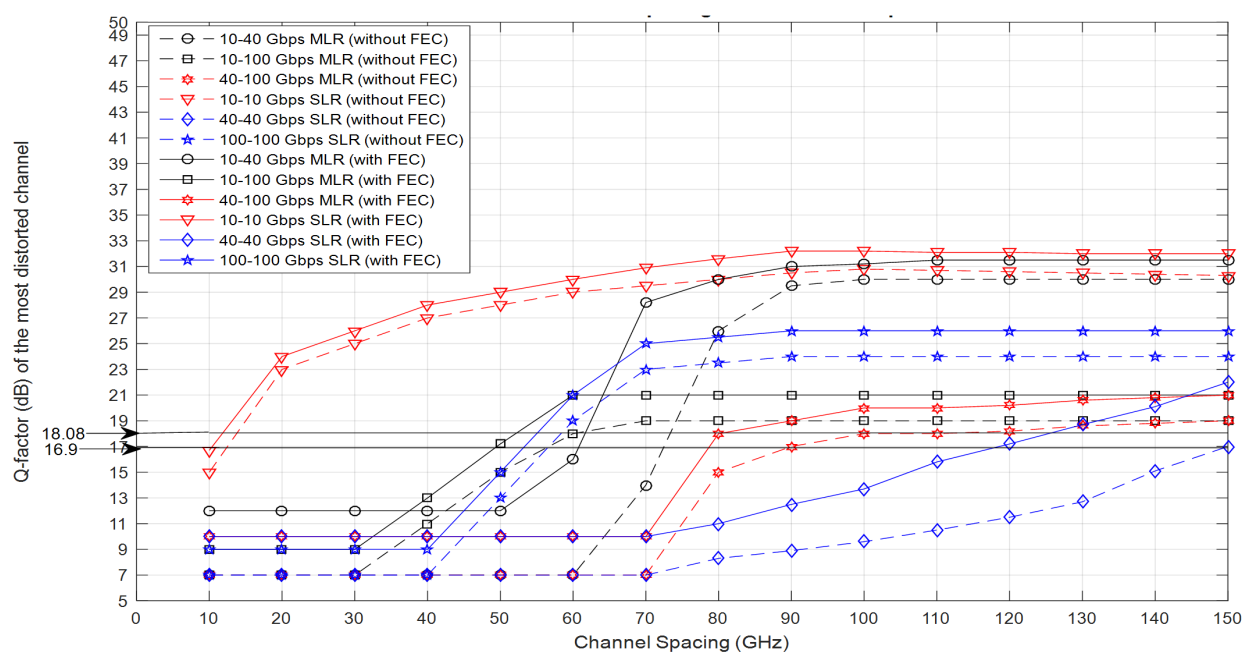

(b)

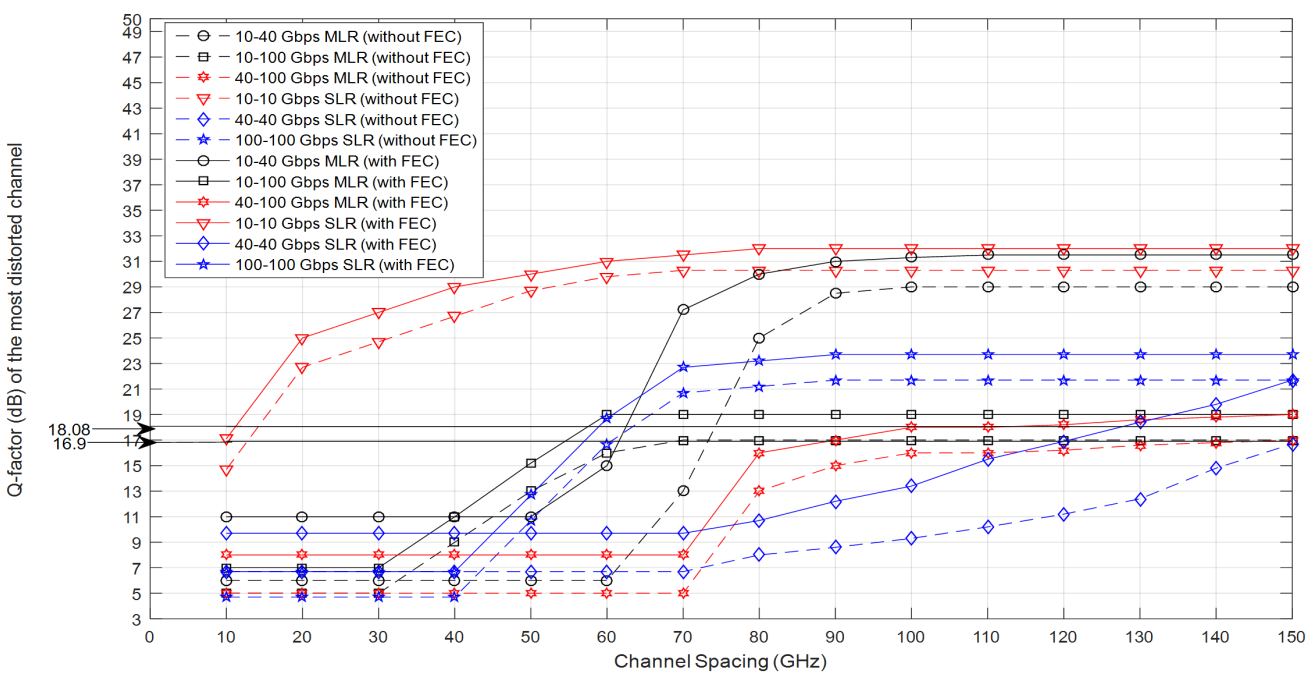

(c)

Fig. 4. $Q$-factor variation for the most distorted channel with respect to channel spacing for WDM system with/without FEC for SMF span length of (a) 50 $\mathrm{km}$, (b) $80 \mathrm{~km}$, and (c) $120 \mathrm{~km}$. 


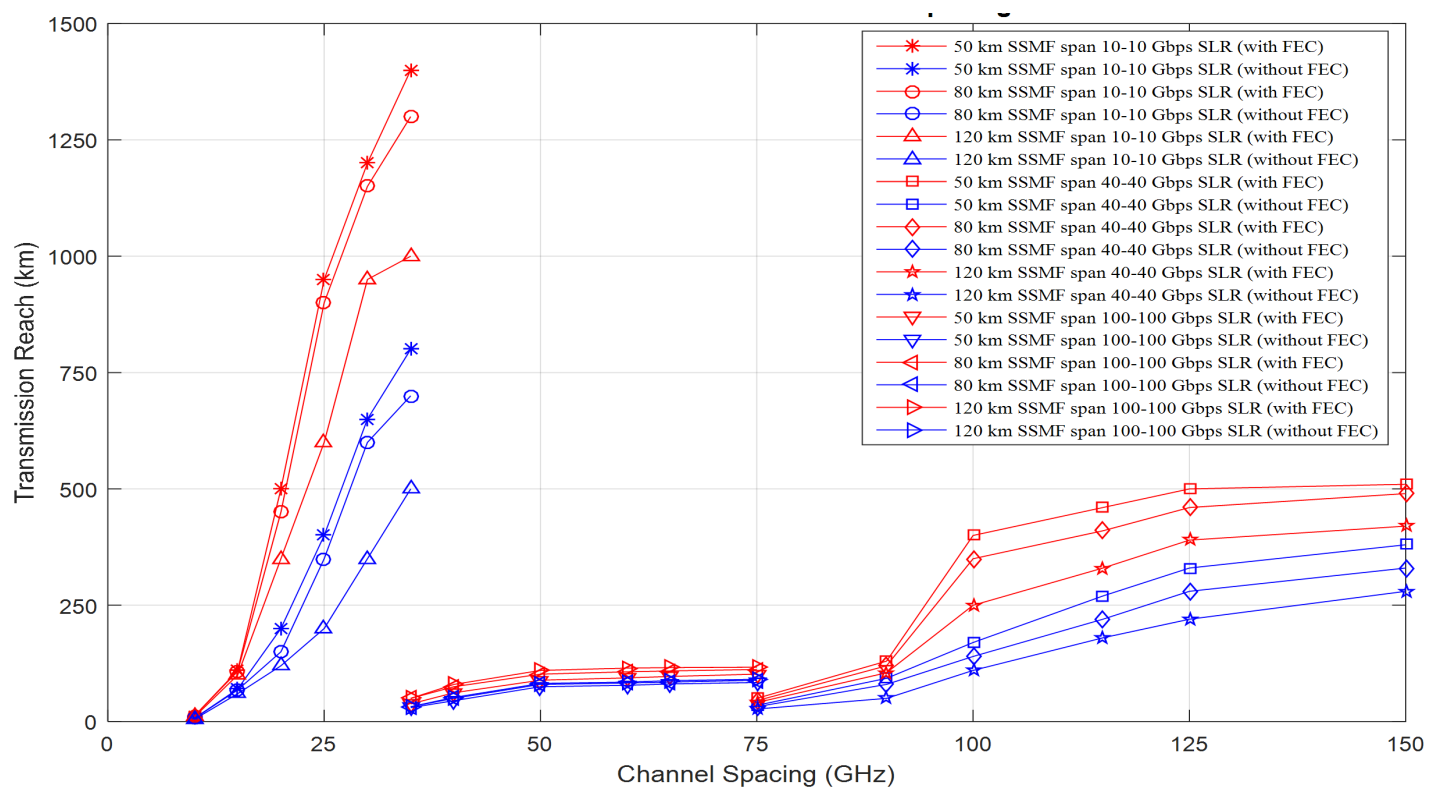

Fig. 5. TR versus channel spacing for a WDM system with and without FEC, and various SSMF spans.

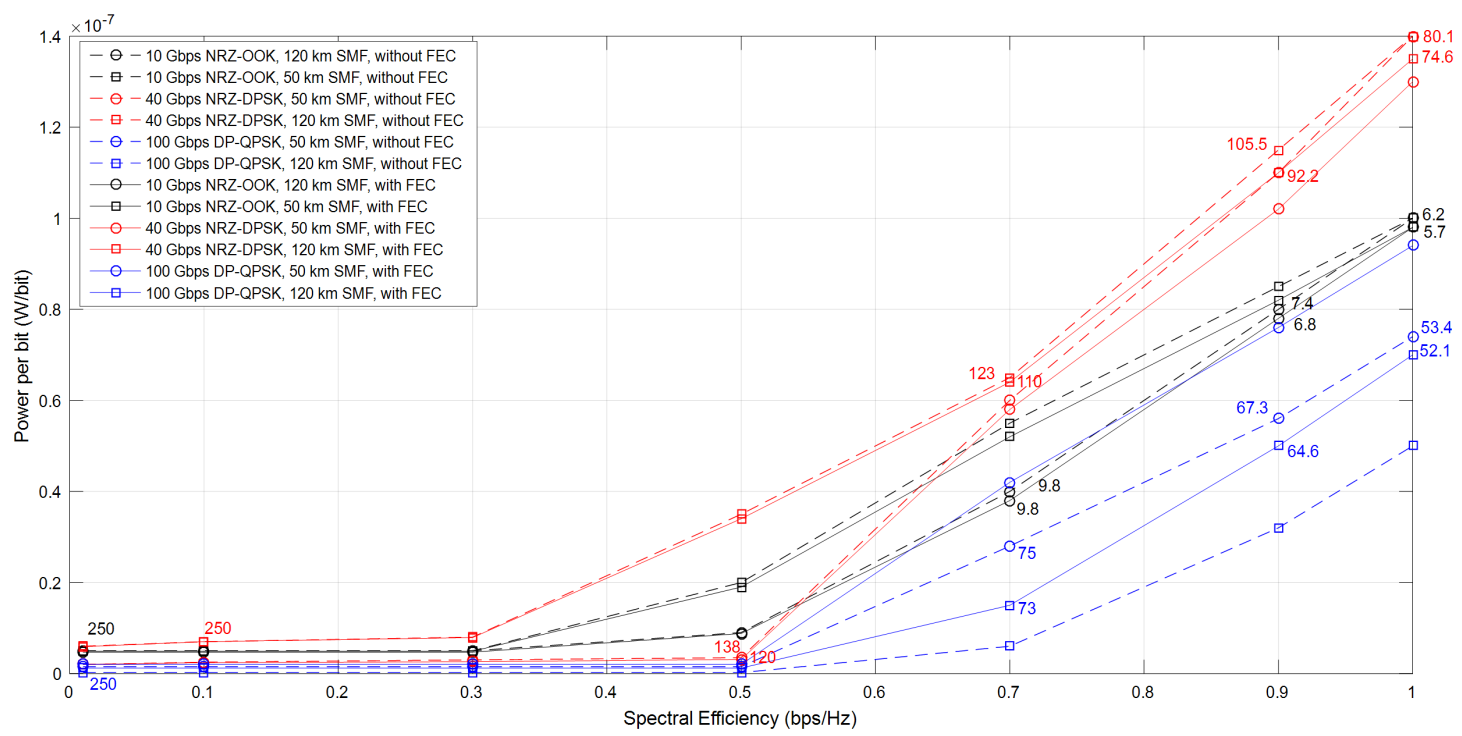

Fig. 6. PE and SE trade-off for transmission capacity of $1 \mathrm{Tbps}$, with the traffic transmitted for $3500 \mathrm{~km}$ of the link. Numbers marked in the graph denote the sub-band spacing values which are needed to obtain a specific SE.

1) Maximum $Q$-factor values are obtained for a system with FEC and $50 \mathrm{~km}$ long SSMF span, and after exceeding a certain value of channel spacing, for all SLR cases, the $Q$-factor values do not increase any further.

2) Irrespective of the SSMF span length and FEC usage, the maximum $Q$-factor value is obtained at a channel spacing value of (i) $90 \mathrm{GHz}$ for $10 \mathrm{G}$ NRZ-OOK systems, (ii) 150 $\mathrm{GHz}$ for 40G NRZ-DPSK systems, and (iii) $100 \mathrm{GHz}$ for 100G DP-QPSK systems.

3) Maximum $Q$-factor value depends on both, the SSMF span length and the presence or the absence of FEC. Specifically, a system with lower span length and with FEC outperforms a system with longer span length and no FEC capability.
4) For a system with FEC, if the BER value cannot exceed $10^{-15}(Q=8)$, the minimum channel spacing values are: (i) for $10 \mathrm{G}$ NRZ-OOK $-9.8 \mathrm{GHz}$ with $50 \mathrm{~km}$ span length, $11.2 \mathrm{GHz}$ with $80 \mathrm{~km}$ span length, $12.4 \mathrm{GHz}$ with 120 $\mathrm{km}$ span length, (ii) for 40G NRZ-OOK - $120 \mathrm{GHz}$ with $50 \mathrm{~km}$ span length, $125 \mathrm{GHz}$ with $80 \mathrm{~km}$ span length, $130 \mathrm{GHz}$ with $120 \mathrm{~km}$ span length, and (iii) for $100 \mathrm{G}$ NRZ-OOK - 52.1 GHz with $50 \mathrm{~km}$ span length, 54.1 $\mathrm{GHz}$ with $80 \mathrm{~km}$ span length, $59.2 \mathrm{GHz}$ with $120 \mathrm{~km}$ span length.

5) For a system without FEC, if the BER value cannot exceed $10^{-12}(Q=7)$, the least value of channel spacing values are: (i) for $10 \mathrm{G} \mathrm{NRZ-OOK} 9.8 \mathrm{GHz}$ with $50 \mathrm{~km}$ span length, $12.1 \mathrm{GHz}$ with $80 \mathrm{~km}$ span length, $14 \mathrm{GHz}$ 
with $120 \mathrm{~km}$ span length, (ii) for 40G NRZ-OOK - 138 $\mathrm{GHz}$ with $50 \mathrm{~km}$ span length, $149 \mathrm{GHz}$ with $80 \mathrm{~km}$ span length, $150 \mathrm{GHz}$ with $120 \mathrm{~km}$ span length, and (iii) for $100 \mathrm{G}$ NRZ-OOK $-53.4 \mathrm{GHz}$ with $50 \mathrm{~km}$ span length, $55.7 \mathrm{GHz}$ with $80 \mathrm{~km}$ span length, $60.1 \mathrm{GHz}$ with $120 \mathrm{~km}$ span length.

From the above, it can be inferred that the systems with FEC and span lengths of $50 \mathrm{~km}$ present better performance compared to all the other cases. Hence, for the MLR case that follows, within every sub-band, channels are separated based on the previously evaluated spacings, viz., $9.8 \mathrm{GHz}$ between 10G NRZ-OOK; $120 \mathrm{GHz}$ between 40G NRZ-DPSK; and $52.1 \mathrm{GHz}$ between $100 \mathrm{G}$ DP-QPSK. Using these minimum acceptable sub-band spacings, the sub-band separations for the MLR case has been determined. We follow the same assumption(s), the description(s) and the configuration(s) as described in [16]. From the results (see Figs. 4(a), 4(b) and 4(c)], for the MLR case, it can be seen that

1) For a system with FEC and BER value not greater than $10^{-15}$, the minimum channel spacing values are as follows: (i) between $10 \mathrm{G}$ and $40 \mathrm{G}-62.1 \mathrm{GHz}$ with $50 \mathrm{~km}$ span length, $62.7 \mathrm{GHz}$ with $80 \mathrm{~km}$ span length, $63.1 \mathrm{GHz}$ with $120 \mathrm{~km}$ span length, (ii) between $10 \mathrm{G}$ and $100 \mathrm{G}-$ $49.6 \mathrm{GHz}$ with $50 \mathrm{~km}$ span length, $53.1 \mathrm{GHz}$ with 80 $\mathrm{km}$ span length, $57.9 \mathrm{GHz}$ with $120 \mathrm{~km}$ span length, and (iii) between $40 \mathrm{G}$ and $100 \mathrm{G}-78.6 \mathrm{GHz}$ with $50 \mathrm{~km}$ span length, $80 \mathrm{GHz}$ with $80 \mathrm{~km}$ span length, $100 \mathrm{GHz}$ with $120 \mathrm{~km}$ span length.

2) For system with no FEC and BER value less than or equal to $10^{-12}$, minimum channel spacing values are as follows: (i) between $10 \mathrm{G}$ and $40 \mathrm{G}-70.7 \mathrm{GHz}$ with $50 \mathrm{~km}$ span length, $72.6 \mathrm{GHz}$ with $80 \mathrm{~km}$ span length, $73 \mathrm{GHz}$ with $120 \mathrm{~km}$ span length, (ii) between $10 \mathrm{G}$ and $100 \mathrm{G}-$ $49.6 \mathrm{GHz}$ with $50 \mathrm{~km}$ span length, $55 \mathrm{GHz}$ with $80 \mathrm{~km}$ span length, $67 \mathrm{GHz}$ with $120 \mathrm{~km}$ span length, and (iii) between $40 \mathrm{G}$ and $100 \mathrm{G}-79.9 \mathrm{GHz}$ with $50 \mathrm{~km}$ span length, $90 \mathrm{GHz}$ with $80 \mathrm{~km}$ span length, $140 \mathrm{GHz}$ with $120 \mathrm{~km}$ span length.

From the above, again it can be inferred that the systems with FEC and the span lengths of $50 \mathrm{~km}$ present better performance compared to all the other cases. Hence, for the MLR case, the minimum acceptable sub-band spacings are $62.1 \mathrm{GHz}$ between $10 \mathrm{G}$ and $40 \mathrm{G}, 49.6 \mathrm{GHz}$ between $10 \mathrm{G}$ and 100G, and $78.6 \mathrm{GHz}$ between $40 \mathrm{G}$ and $100 \mathrm{G}$.

We used the obtained results from Fig. 4 as the input for determining the TR (see Fig. 5) for various SLR cases. We use the MF, SSMF span length, channel spacing, and previously determined $Q$-factor values after the transmission along one section of the fiber-optical link as the input parameters. From the results it can be observed that

1) The WDM system with FEC and $50 \mathrm{~km}$ long SSMF span provides the longest TR.

2) In the case of $100 \mathrm{G}$ DP-QPSK, it is required to use 80 $\mathrm{km}$ or even $120 \mathrm{~km}$ long SSMF spans, else, a decrease in the regeneration section length occurs.

3) Difference between the regeneration section lengths is negligible, if for the $100 \mathrm{G}$ DP-QPSK MF $80 \mathrm{~km}$ or 120

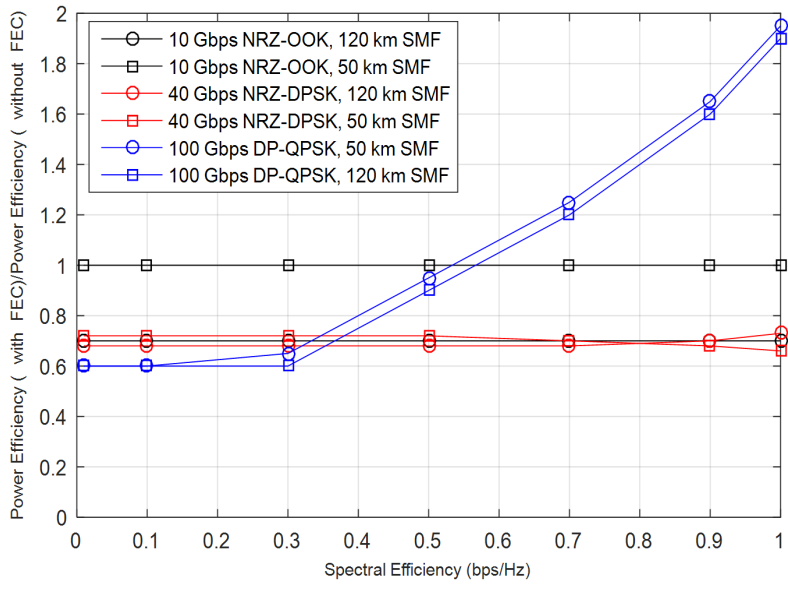

Fig. 7. PE of the WDM systems with and without FEC for a total traffic of 1 Tbps and the link length of $3500 \mathrm{~km}$.

$\mathrm{km}$ long SSMF spans are used.

4) The minimum regeneration section in the case of $100 \mathrm{G}$ DP-QPSK is achievable for the system devoid of FEC, and when the span length of the SSMF is only $50 \mathrm{~km}$.

5) The largest regeneration section length in the WDM system with FEC and $50 \mathrm{~km}$ long SSMF spans exceeds (i) $1400 \mathrm{~km}$, (ii) $500 \mathrm{~km}$ and (iii) $100 \mathrm{~km}$, in cases of $10 \mathrm{G}$ NRZ-OOK, 40G NRZ-DPSK and 100G DP-QPSK MFs, respectively.

6) The largest regeneration section length in the WDM system with FEC and $80 \mathrm{~km}$ long SSMF spans exceeds (i) $1300 \mathrm{~km}$, (ii) $400 \mathrm{~km}$ and (iii) $80 \mathrm{~km}$, in cases of $10 \mathrm{G}$ NRZ-OOK, 40G NRZ-DPSK and 100G DP-QPSK MFs, respectively.

7) The largest regeneration section length in the WDM system with FEC and $120 \mathrm{~km}$ long SSMF spans exceeds (i) $1000 \mathrm{~km}$, (ii) $200 \mathrm{~km}$ and (iii) $60 \mathrm{~km}$, in cases of $10 \mathrm{G}$ NRZ-OOK, 40G NRZ-DPSK and 100G DP-QPSK MFs, respectively.

\section{Spectral efficiency versus power-efficiency trade-off}

In this section we identify the SE values and the SSMF span lengths at which the WDM system provides a low power per bit. The SE and the PE relationship is investigated in both, the SLR and the MLR system, and with and without the FEC capabilities. In SLR systems for analyzing the PE, variation of consumed power for transmitting a single bit of constant signal QoT is considered, that is also SE dependent. The span lengths of $50 \mathrm{~km}$ and $120 \mathrm{~km}$ are considered for the investigations. The traffic is assumed to be transmitted for $3500 \mathrm{~km}$ of the link. Next to each curve within the results (see Fig. 6), numbers are marked which denote the spacing values of the sub-band that are needed to obtain a particular value of the SE. From Fig 6 , it can be observed that:

1) In the case of $10 \mathrm{G}$ NRZ-OOK and 40G NRZ-DPSK, for low values of $\mathrm{SE}$, power per bit values in the presence and the absence of FEC, for either SMF span values, is approximately the same. However, as the SE increases (approximately greater than $0.35 \mathrm{bps} / \mathrm{Hz}$ ), a system with 


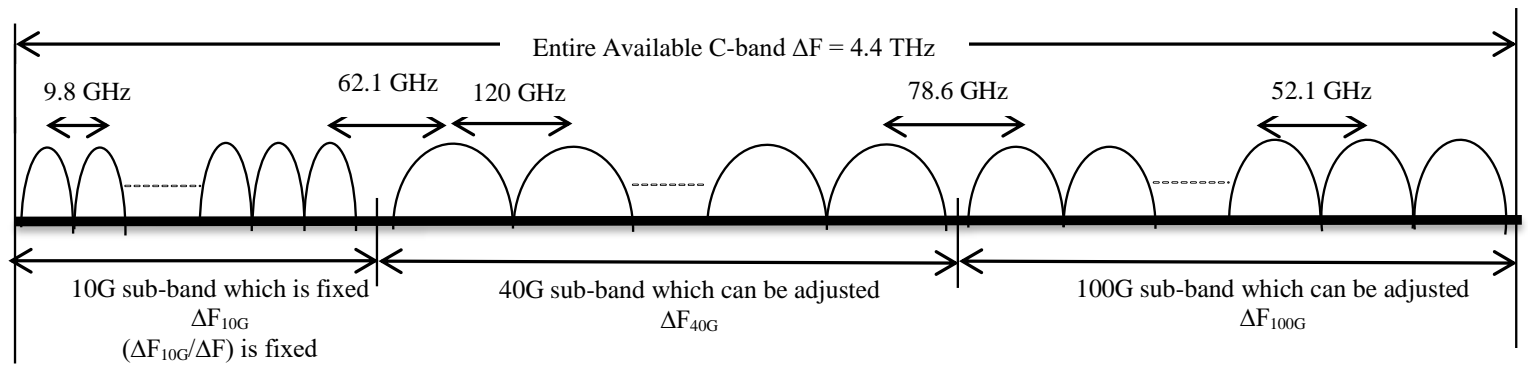

Fig. 8. MLR and SLR WDM systems sub-band and channel spacings.

FEC starts to show lower power per bit values compared to a system without FEC.

2) For a $10 \mathrm{G}$ wavelengths system with larger sub-band spacing, irrespective of presence or absence of FEC, in comparison to a system with $50 \mathrm{~km}$ SMF span length, using a $120 \mathrm{~km}$ SMF span ensures lesser power consumption. However, for lesser sub-band spacing, reduction in consumed power is achieved if a $50 \mathrm{~km}$ SMF span length is used.

3) For the 40G NRZ-DPSK system with a value of sub-band spacing greater than (i) $138 \mathrm{GHz}$ without FEC, and (ii) $120 \mathrm{GHz}$ with FEC, lesser power per bit is achieved for a $50 \mathrm{~km}$ long SMF span in comparison to when the SMF span length is $120 \mathrm{~km}$. However, with decrease in subband spacing values, difference in the PE also minimizes when the SMF spans between $50 \mathrm{~km}$ and $120 \mathrm{~km}$. Also, difference in PE disappears at approximately the least desired sub-band spacing value of (i) $80 \mathrm{GHz}$ for system without FEC, and (ii) $72 \mathrm{GHz}$ for a system with FEC.

4) When the SE value is fixed, the use of $100 \mathrm{G}$ DPQPSK requisites minimum power per bit for transmitting the data. Also, for the $100 \mathrm{G}$ DP-QPSK cases, using a longer SMF span (i.e. $120 \mathrm{kms}$ ) length permits reduction of the consumed power. Further, as the SE increases approximately above $0.5 \mathrm{bps} / \mathrm{Hz}$, a system without FEC starts to show lower power per bit values compared to a system without FEC.

Finally, it can be inferred that, for all the considered SLR cases, SSMF span lengths vary with the SE, and for higher LRs (i.e., 100G), systems without FEC provide lower power per bit than same solutions with FEC. Further, for comparison, we have also evaluated the ratio of PE, with and without FEC respectively, versus the SE (see Fig. 7). From Fig. 7 it can be observed that, in terms of PE, a system without FEC outperforms a system with FEC only in the case of $100 \mathrm{G}$ DP-QPSK, and when the SE is set close to or equal to the maximum acceptable value. Also, the power savings are seen to increase with number of $3 \mathrm{R}$ operations. For e.g., the power savings are more than $50 \%$ for a capacity of 1 Tbps and TR of $3500 \mathrm{~km}$ (see Fig. 7). However, it must be noted that for some other combinations of SE, capacity and SSMF span length(s), the 10G NRZ-OOK and 40G NRZ-DPSK systems without FEC could be more power efficient compared to the systems without FEC, which will be the scope of our future work.
In MLR systems, allotment of the varied DR wavelength channels (e.g. 10/40/100G) to a frequency band defines the PE. Further, width of every sub-band may change based on division between the varied (i.e., 10/40/100G) wavelengths. Hence, the width of the individual sub-band, spacing of the channel within the individual sub-band, and spacing of the sub-band, pre-allocates the individual wavelengths numbers that can be collated within a band of frequency. In this work, within every sub-band, we divide the channels using the evaluated spacings - $9.8 \mathrm{GHz}$ between 10G NRZ-OOK, $120 \mathrm{GHz}$ between 40G NRZ-DPSK, and $52.1 \mathrm{GHz}$ between $100 \mathrm{G}$ DP-QPSK. Also, division of sub-bands is done as per the minimum sub-band spacings - $62.1 \mathrm{GHz}$ between 10G$40 \mathrm{G}, 49.6 \mathrm{GHz}$ between 10G-100G, and $78.6 \mathrm{GHz}$ between 40G-100G. The design of chosen MLR system assumes that (i) each demand needs all the designated wavelength channels, and (ii) entire C-band frequency $(\Delta \mathrm{F}=4.4 \mathrm{THz})$ [17], [21], is available for the transmission.

Further, the complete C-band is divided into individual subbands, one for each LR, viz., $\Delta \mathrm{F}_{10 \mathrm{G}}$ for $10 \mathrm{Gbps}, \Delta \mathrm{F}_{40 \mathrm{G}}$ for $40 \mathrm{Gbps}$, and $\Delta \mathrm{F}_{100 \mathrm{G}}$ for $100 \mathrm{Gbps}$. In the simulations, the 10G sub-band width over the $\mathrm{C}$-band is fixed i.e., the ratio of allocated frequency to $10 \mathrm{G}$ sub-band and frequency of the complete C-band (i.e. $\Delta \mathrm{F}_{10 \mathrm{G}} / \Delta \mathrm{F}$ ) is fixed. Fig. 8 shows the sub-band and the channel spacings for a MLR and SLR design, respectively. The $\mathrm{X}$-axis of Fig. 9 and 10 shows the fixed values of $\Delta \mathrm{F}_{10 \mathrm{G}} / \Delta \mathrm{F}$.

We vary $\Delta \mathrm{F}_{40 \mathrm{G}}$ and $\Delta \mathrm{F}_{100 \mathrm{G}}$ as follows: (i) $\Delta \mathrm{F}_{100 \mathrm{G}}$ al-

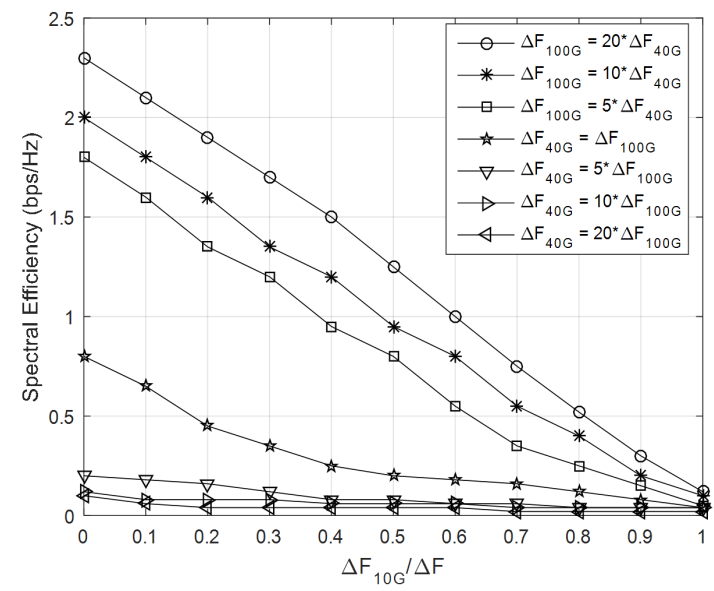

Fig. 9. SE in the complete C-band. 


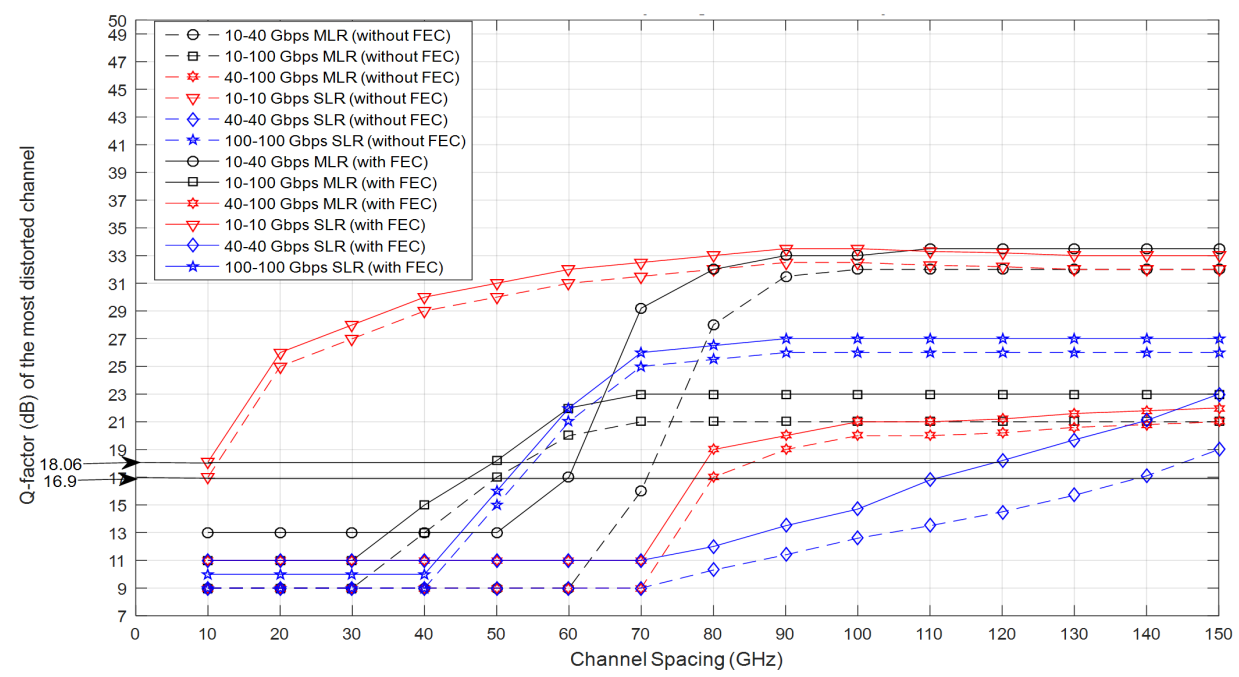

(a)

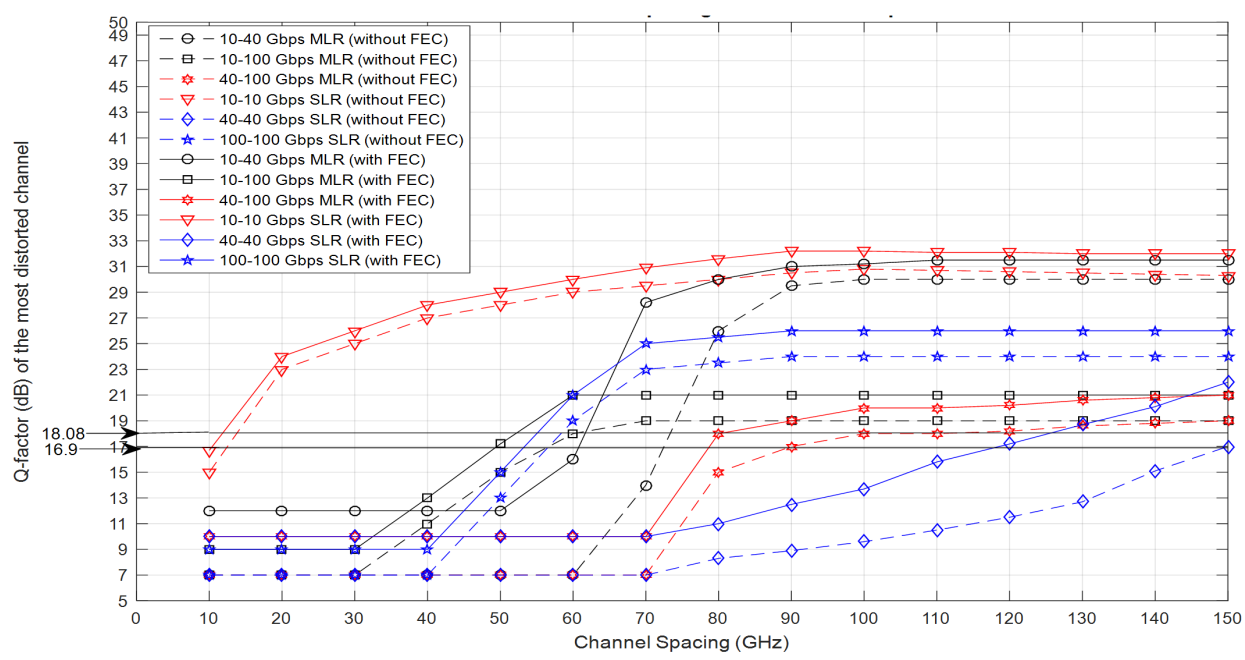

(b)

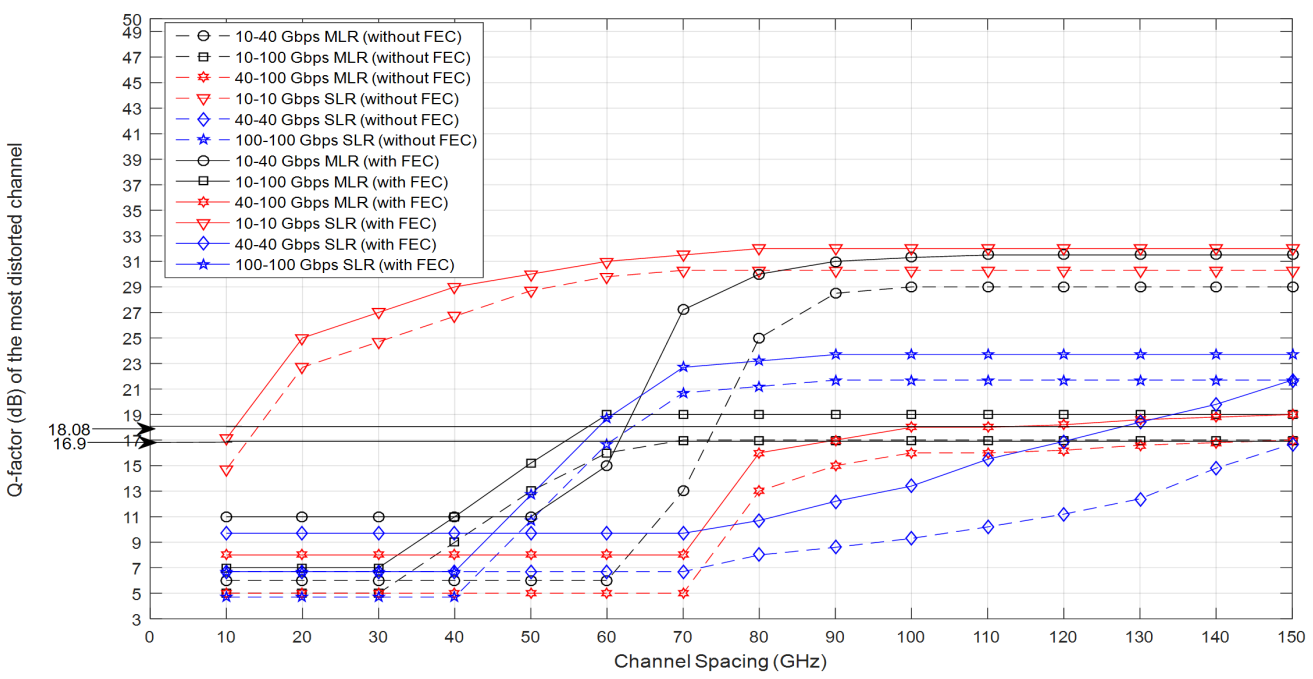

(c)

Fig. 10. PE versus width of the individual sub-band for a link length of (a) $50 \mathrm{~km}$, (b) $500 \mathrm{~km}$, and (c) $1000 \mathrm{~km}$.

lotted frequency equals that of $\Delta \mathrm{F}_{40 \mathrm{G}}\left(\Delta \mathrm{F}_{100 \mathrm{G}}=\Delta \mathrm{F}_{40 \mathrm{G}}\right)$, (ii) $\Delta \mathrm{F}_{100 \mathrm{G}}$ allotted frequency is 5 times that of $\Delta \mathrm{F}_{40 \mathrm{G}}$
$\left(\Delta \mathrm{F}_{100 \mathrm{G}}=5 \cdot \Delta \mathrm{F}_{40 \mathrm{G}}\right)$, (iii) $\Delta \mathrm{F}_{100 \mathrm{G}}$ allotted frequency is 10 times that of $\Delta \mathrm{F}_{40 \mathrm{G}}\left(\Delta \mathrm{F}_{100 \mathrm{G}}=10 \cdot \Delta \mathrm{F}_{40 \mathrm{G}}\right)$, (iv) $\Delta \mathrm{F}_{100 \mathrm{G}}$ allot- 


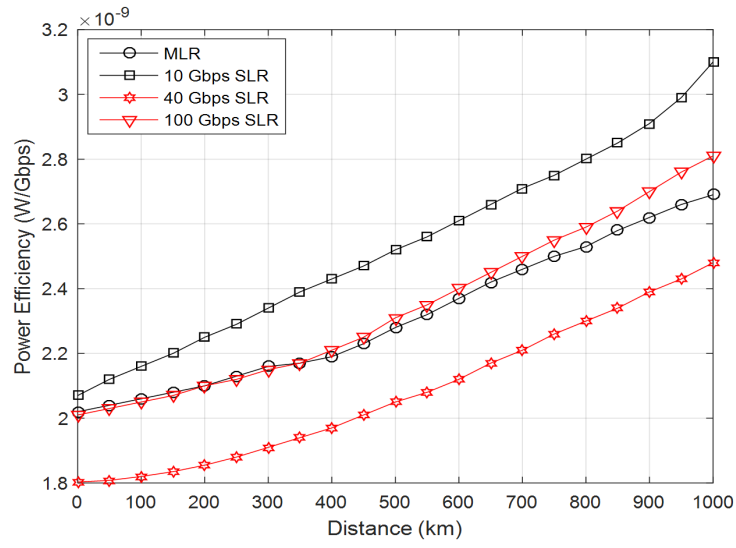

Fig. 11. Variation of PE with transmission distance for different SLR and realistic demand distribution MLR system.

ted frequency is 20 times that of $\Delta \mathrm{F}_{40 \mathrm{G}}\left(\Delta \mathrm{F}_{100 \mathrm{G}}=20 \cdot \Delta \mathrm{F}_{40 \mathrm{G}}\right)$, (v) $\Delta \mathrm{F}_{40 \mathrm{G}}$ allotted frequency is 5 times that of $\Delta \mathrm{F}_{100 \mathrm{G}}$ $\left(\Delta \mathrm{F}_{40 \mathrm{G}}=5 \cdot \Delta \mathrm{F}_{100 \mathrm{G}}\right),(\mathrm{vi}) \Delta \mathrm{F}_{40 \mathrm{G}}$ allotted frequency is 10 times that of $\Delta \mathrm{F}_{100 \mathrm{G}}\left(\Delta \mathrm{F}_{40 \mathrm{G}}=10 \cdot \Delta \mathrm{F}_{100 \mathrm{G}}\right)$, and (vii) $\Delta \mathrm{F}_{40 \mathrm{G}}$ allotted frequency is 20 times that of $\Delta \mathrm{F}_{100 \mathrm{G}}\left(\Delta \mathrm{F}_{40 \mathrm{G}}=20 \cdot \Delta \mathrm{F}_{100 \mathrm{G}}\right)$. Further, the span lengths are varied as $50 \mathrm{~km}, 500 \mathrm{~km}$, and $1000 \mathrm{~km}$ respectively.

Fig. 9 shows the variation of $\mathrm{SE}$ in the $\mathrm{C}$-band with the width of each sub-band. It can be observed that there is an increase in the SE when there is a utilization of multiple channels which operate at a higher DR MFs (i.e., $\Delta \mathrm{F}_{100 \mathrm{G}}=20 \cdot \Delta \mathrm{F}_{40 \mathrm{G}}$, $\Delta \mathrm{F}_{100 \mathrm{G}}=10 \cdot \Delta \mathrm{F}_{40 \mathrm{G}}$, and/or $\left.\Delta \mathrm{F}_{100 \mathrm{G}}=5 \cdot \Delta \mathrm{F}_{40 \mathrm{G}}\right)$.

On the other hand, a very low SE is obtained when the value of $100 \mathrm{G}$ channels is reduced (i.e., $\Delta \mathrm{F}_{40 \mathrm{G}}=5 \cdot \Delta \mathrm{F}_{100 \mathrm{G}}$ or $\Delta \mathrm{F}_{40 \mathrm{G}}=10 \cdot \Delta \mathrm{F}_{100 \mathrm{G}}$ or $\Delta \mathrm{F}_{40 \mathrm{G}}=20 \cdot \Delta \mathrm{F}_{40 \mathrm{G}}$ ). However, when the connection distance increases, utilization of $100 \mathrm{G}$ channels shows drawbacks as shown by PE results in Fig. 10 .

Fig. 10(a) shows variation of PE with width of every subband, for various values of the connection length. It can be observed from Fig. 10(a) that when connection distance is restricted to only $50 \mathrm{~km}$, solution with $\Delta \mathrm{F}_{100 \mathrm{G}}=20 \cdot \Delta \mathrm{F}_{40 \mathrm{G}}$ is the most power efficient solution; whereas, the worst power efficient solution is one with $\Delta \mathrm{F}_{40 \mathrm{G}}=20 \cdot \Delta \mathrm{F}_{100 \mathrm{G}}$. However, the situation changes when transmission distance increases.

Fig. 10(b) and Fig. 10(c) show the results for PE when the connection distance is $500 \mathrm{~km}$ and $1000 \mathrm{~km}$, respectively. It can be observed that when $\Delta \mathrm{F}_{10 \mathrm{G}}=0$, resorting to $\Delta \mathrm{F}_{100 \mathrm{G}}$ $=20 \cdot \Delta \mathrm{F}_{40 \mathrm{G}}, \Delta \mathrm{F}_{100 \mathrm{G}}=10 \cdot \Delta \mathrm{F}_{40 \mathrm{G}}$, and $\Delta \mathrm{F}_{100 \mathrm{G}}=5 \cdot \Delta \mathrm{F}_{40 \mathrm{G}}$ shows the worst PE. The reason for the aforementioned is that, compared to the $40 \mathrm{G}$ TSPs, $\Delta \mathrm{F}_{100 \mathrm{G}}$ relies on the $100 \mathrm{G}$ TSPs whose $\mathrm{PE}$ is lower in regard to regeneration of the signals. For both values of connection distances, it is also observed that, only after a particular value of $\Delta \mathrm{F}_{10 \mathrm{G}}$ has been crossed, there occurs an advantage in using the $100 \mathrm{G}$ TSPs i.e., allocating $\Delta \mathrm{F}_{100 \mathrm{G}}=20 \cdot \Delta \mathrm{F}_{40 \mathrm{G}}, \Delta \mathrm{F}_{100 \mathrm{G}}=10 \cdot \Delta \mathrm{F}_{40 \mathrm{G}}$, and $\Delta \mathrm{F}_{100 \mathrm{G}}=$ $5 \cdot \Delta \mathrm{F}_{40 \mathrm{G}}$. Further, for all the considered MLR designs, before, and at this particular value of F10G, approximately equal power consumption is needed for the transmission of one bit. Hence, at this point of equal PE, where the various MLR designs combine, consumption of the power for transmission does not depend on the distribution of the frequency band between the 10/40/100G wavelengths. Also, location of the point of equal PE depends on the link length and values of the TSP and $3 \mathrm{R}$ power consumptions.

Lastly, it can be inferred that in MLR systems, SE and $\mathrm{PE}$ can be enhanced by resorting to (i) links which are shorter with larger bandwidth assignment to the 100G DPQPSK wavelengths, or (ii) links which are longer with larger bandwidth assignment to the 40G NRZ-DPSK wavelengths.

\section{Spectral efficiency versus power-efficiency trade-off}

In [16], for different SLR and MLR solutions, we have evaluated the relationship between the PE and the connection distance. However, our analysis assumed that the demands are equally distributed among the 10/40/100 Gbps requests, i.e., $\Delta \mathrm{F}_{10 \mathrm{Gbps}}=\Delta \mathrm{F}_{40 \mathrm{Gbps}}=\Delta \mathrm{F}_{100 \mathrm{Gbps}}=33 \%$, and also, that system is not FEC capable.

In the current study, we consider a demand distribution that is realistic over the 10/40/100G sub-bands viz., 50:35:15 [28] for a system with FEC capabilities. Based on the values of the channel and the sub-band spacings (see Fig. 9 and Fig. 10, , and under the assumption of every demand requiring an entire wavelength channel, a 50:35:15 demand distributions translates into $\Delta \mathrm{F}_{10 \mathrm{Gbps}}=10 \%, \Delta \mathrm{F}_{40 \mathrm{Gbps}}=73 \%$ and $\Delta \mathrm{F}_{100 \mathrm{Gbps}}=15 \%$ of the complete C-band. From Fig. 11, it is observed that in regard to $\mathrm{PE}$, performance of this particular MLR design is

1) always exceeding the performance of the 10G SLR,

2) better than that of $100 \mathrm{G}$ SLR for distances exceeding 400 $\mathrm{km}$; (ii) similar to that of the $100 \mathrm{G}$ SLR, for distances between $300-400 \mathrm{~km}$; (iii) worst compared to the $100 \mathrm{G}$ SLR for distances lower than $300 \mathrm{~km}$.

3) always worst than the $40 \mathrm{G}$ SLR, for any transmission distance.

Lastly, as a remark, an extension of the current study can focus on the consideration of various other values of demand distributions between the 10/40/100G requests, and with a system with and without FEC capabilities.

\section{CONCLUSION}

Focusing on multiple SLR and MLR WDM systems, for a constant QoT, we compared the PE, and also evaluated the minimum channel spacing values. We also proposed an improved DWDM grating system using which, in conjunction with the unequal frequency intervals, compared to the ITU$\mathrm{T}$ fixed DWDM grating, SE of the frequency band can be doubled. Further, the trade-off between the SE and the PE has also been investigated in both, the SLR and the MLR systems.

The results show that in the MLR systems, using 100G TSPs with $40 \mathrm{G} 3 \mathrm{Rs}$ leads to the largest PE. Also, with increase in the transmission distance or the SE, due to the requirement of more regeneration, instead of TSPs, the 3Rs define power consumption values needed for transmission. The system with FEC and lower span length show better performance compared to all the other cases. In the SLR systems, the highest SE and the lowest power consumption is secured by use of $100 \mathrm{G}$ DP-QPSK. In regard to the $10 \mathrm{G}$ NRZ-OOK and the 40G NRZ-DPSK, SE varies with the SSMF span lengths, the 
total traffic, and the link length. Further, for higher line rate of $100 \mathrm{G}$, a system without FEC provides lower power per bit than similar solutions with FEC. The MLR system (i) always outperforms the $10 \mathrm{G}$ SLR systems; (ii) performance is dependent on the transmission distance, compared to the $100 \mathrm{G}$ SLR systems, and (iii) performance is always worst, compared to the 40G SLR systems. The SE and PE improvement in the MLR systems can be ensured by resorting to (i) links which are shorter with larger bandwidth assignment to 100G DPQPSK wavelengths, or (ii) links which are longer with higher bandwidth assignment to the 40G NRZ-DPSK wavelengths.

The results also make it evident that increase in SE can be ensured by using many channels which operate at high line rate MFs; however, as the transmission distances increases, such MFs start to show drawbacks. Further, for longer distances, a point of equal PE occurs, where, for the different SLR and MLR designs; consumed power does not depend on distribution of the frequency band. The location of this equal $\mathrm{PE}$ is dependent on both, length of the link, and values of the consumed power of the TSPs and the 3Rs. Finally, the results also indicate that with increase in the SE, simultaneously, focus must also be on the reduction of the power consumption.

\section{REFERENCES}

[1] A.C. Wietfeld, Modeling, simulation and analysis of optical time division multiplexing transmission systems, Ph.D. dissertation, Der Technischen Fakultaet der Universitaet Erlangen-Nuernberg, 2004.

[2] Cisco Systems Inc. Cisco visual networking index: forecast and methodology 20132018. White paper, pp 1-14, 2014

[3] S. Gosselin and M. Joindot, Key drivers and technologies for future optical networks, in Proc. IEEE ECOC, Tutorial We2.2.1, 2006.

[4] S.P. Singh, S. Sengar, R. Bajpai, and S. Iyer, Next-Generation VariableLine-Rate Optical WDM Networks: Issues and Challenges, J. Opt Commun., De Gruyter, vol. 34, no. 1, pp. 331-350, 2013.

[5] P. Chowdhury, M. Tornatore, A. Nag, E. Ip, T. Wang, and B. Mukherjee, On the design of energy-efficient mixed-line-rate (MLR) optica networks, IEEE/OSA J. Lightw. Technol., vol. 30, pp. 130-139, 2012.

[6] N. Sambo, M. Secondini, F. Cugini, G. Bottari, and P. Iovanna, Modeling and distributed provisioning in $1040100-\mathrm{Gb} / \mathrm{s}$ multirate wavelength switched optical networks, IEEE/OSA J. Lightw. Technol., vol. 29, pp. 1248-1257, 2011.

[7] J.L. Vizcaino, Y. Ye, and I.T. Monroy, Energy efficiency in elasticbandwidth optical networks, in Proc. IEEE NOF, pp. 107-111, 2011.

[8] E. Lebel. Get excited about 100G. Lightwave online, Live Webcast, 2011.

[9] Y. Miyamoto, Ultra High Capacity Transmission for Optical Transport Networks, in Proc. OFC/NFOEC, OThX4, 2011.

[10] A. Sano, H. Masuda, T. Kobayashi, M. Fujiwara, K. Horikoshi, E. Yoshida, Y. Miyamoto, M. Matsui, M. Mizoguchi, H. Yamazaki, Y Sakamaki, and H. Ishii, Ultra-High Capacity WDM Transmission Using Spectrally-Efficient PDM 16-QAM Modulation and C- and Extended LBand Wideband Optical Amplification, IEEE/OSA J. Lightw. Technol. vol. 29, no. 4. pp. 578-586, 2011.

[11] J.L. Vizcaino, Y. Ye, and I.T. Monroy, Energy efficiency analysis for flexible-grid OFDM based optical network, Computer Networks, Elsevier, vol. 56, no. 10, pp. 2400-2419, 2012.

[12] W.V. Heddeghem, F. Izdikowski, W. Vereecken, D. Colle, M. Pickavet, and P. Demester, Power consumption modeling in optical multilayer networks, Photonic Netw. Commun., Springer, vol. 24, pp. 86-102, 2012.

[13] Green Touch: ICT industry combats climate change/Internets. Available: http://www.greentouch.org/index.php?page=howtheictindustriescan helptheworldcombatclimatechange

[14] C. Cavdar, M. Ruiz, P. Monti, L. Velasco, and L. Wosinska, Design of Green Optical Networks with Signal Quality Guarantee, in Proc. IEEE ICC, pp.3025, 2012.

[15] G. Rizzelli, A. Morea, M. Tornatore, and O. Rival, Energy efficien traffic-aware design of on-off multi-layer translucent optical network, Journal of Computer Networks, vol. 56, no. 10, pp. 2443-2455, 2012.
[16] S. Iyer and S.P. Singh, Spectral and power efficiency investigation in single- and multi-line-rate optical wavelength division multiplexed (WDM) networks, Photonic Netw. Commun., Springer, vol. 33, no. 1, pp. 39-51, 2017.

[17] G. P. Agrawal, Fiber-Optic Communication Systems, Wiley: London, 2010.

[18] RSoft Design Group Inc: Coherent PM-QPSK versus RZ$D Q P S K$ and DPSK for high bitrate systems. Available: http://www.rsoftdesign.com/products.php?sub=System+and+Network \&itm=OptSim\&det=Application+Gallery $\&$ id $=50$

[19] P.J. Winzer, and R.J. Essiambre, Advanced Optical Modulation Formats, in Proc. IEEE, vol. 94, pp. 952-985, 2006.

[20] S. Iyer and S.P Singh, Impact of Channel Dynamics, Combined Nonlinearities and ASE Noise on Transmission Performance of all Optical Star WDM Networks, Commun. Netw. Sci. Res., vol. 3, no. 4, pp. 235-249, 2011.

[21] R. Ramaswami, K.N. Sivarajan, and G.H. Sasaki, Optical Networks: A Practical Perspective, Elsevier, 2010.

[22] MRV: Lambda Driver DWDM 40Gbps transponder (TM-40GT8, 2011)/Internets. Available:http://www.mrv.com/datasheets/LD/PDF300/MRV-LDTM-40GT8_HI.pdf

[23] ADVA: FSP 3000 coherent transponders, fact sheet (2012)/Internets. Available:http://www.advaoptical.com/ /media/Innovation/Efficient\%20100G\%20Transport/ 100G\%20Coherent\%20Transponder.ashx

[24] Ciena: F10-T 10G transponder, datasheet (2011)/Internets. Available: http://www.ciena.com/products/f10t/tab/features/

[25] A. Morea, S. Spandaro, O. Rival, J. Perello, F. Agraz, and D. Verchere, Power management of optoelectronic interfaces for dynamic optical networks, in Proc. IEEE ECOC, We.8.K.3.pdf, pp. 1-3, 2011.

[26] Civcom Devices \& Systems Ltd. 100G DP(D) QPSK coherent tunable transponder. Datasheet. DOC1190100, 2014.

[27] ITU-T Recommendation G.694.1. Spectral grids for WDM applications: DWDM frequency grid- Series G: Transmission Systems and Media, Digital Systems and Networks. 2012.

[28] O. Rival, and A. Morea, Resource Requirements in Mixed-Line Rate and Elastic Dynamic Optical Networks, in Proc. OFC/NFOEC, pp. 1-3, 2012.

Sridhar Iyer received B.E. degree in Electronics and Telecommunications Engineering from Mumbai University, India in 2005, M.S degree in Electrical and Communication Engineering from New Mexico State University, U.S.A in 2008, and the Ph.D. degree from Delhi University, India in 2017. He worked as an Assistant Professor in the Department of ECE at NIIT University, and Christ University, India between 2012-2016. Currently he is an Associate Professor in the Department of ECE, Jain College of Engineering, India. His research interests include the architectural, algorithmic, and performance aspects of the optical networks, with current emphasis on efficient design and resource optimization in the flexi-grid Elastic optical networks. Dr. Iyer has published over 35 peer-reviewed articles in the aforementioned areas.

Shree Prakash Singh received his B.E. degree in Electronics and Communication Engineering from MMM Engineering College, Gorakhpur, India, in 1990 and M.Tech. degree from REC, Kurukshetra, India, in 1994. He holds a Doctoral Degree in Optical Networks from the Indian Institute of Technology, Delhi (IITD), India, in 2007. During 1994-2000, he worked as Lecturer in the Department of Electronics and Computer Engineering at REC Kurukshetra. In October 2000, he joined as Lecturer in the Department of Electronics, Netaji Subhas Institute of Technology (formally known as Delhi Institute of Technology New Delhi). Presently he is Professor at the Division of Electronics and Communication Engineering, Netaji Subhas Institute of Technology, New Delhi. His current area of research is Optical Networks, Optical wireless communication. 